\title{
PASSEIOS DANÇANTES NAS RUAS DE PELOTAS: PREPARANDO-SE PARA O DESCONHECIDO
}

\author{
Débora Souto Allemand \\ Professora Substituta no Curso de Dança-Licenciatura da Universidade Federal de Pelotas. \\ Mestre em Arquitetura e Urbanismo pela Universidade Federal de Pelotas \\ deborallemand@hotmail.com \\ Carmen Anita Hoffmann \\ Professora do Curso de Dança-licenciatura da Universidade Federal de Pelotas. \\ Doutora em História pela Pontifícia Universidade Católica do Rio Grande do Sul \\ carminhalese@yahoo.com.br \\ Taís Bastos Botelho \\ Graduanda em Dança-Licenciatura UFPel. Bolsista do Projeto de Extensão "Caminhos da Dança na Rua" \\ taissbbastos@gmail.com \\ Alice Braz Iturriet \\ Graduanda em Dança-Licenciatura UFPel. Bolsista do Projeto de Extensão "Caminhos da Dança na Rua" \\ aliceb.iturriet@hotmail.com
}

O presente texto se refere ao projeto de extensão Caminhos da Dança na Rua, do Curso de Dança-licenciatura da UFPel, que trata da trajetória dança-arquitetura-cidade. O objetivo central do trabalho é discutir a respeito da impossibilidade de separação da preparação corporal e dos "produtos" poéticos surgidos no decorrer das atividades. Como aporte teórico foram utilizados os autores: Cohen (2004), Freitas (2011), Jacques (2002 e 2008), Miranda (2008), Rancière (2008) e Silva (2005). O projeto se desenvolve em encontros em "espaços seguros" (sala de aula) e "espaços de risco" (cidade), com experimentações de técnicas de conscientização corporal, buscando a relação dos participantes entre si e com o espaço público, quanto à sua fisicalidade e características sociais, refletindo em diferentes poéticas. A comunidade se envolve direta e indiretamente no processo de experimentação na rua, papéis de espectador e artista se tornam borrados e os participantes têm encontrado outras danças em si mesmos.

Palavras-chave

Cidade. Dança. Intervenções Urbanas. Jogos. Improvisação.
This text is about the Caminhos da Dança na Rua extension project, from the UFpel's Dance Course, which is about the dance-architecturecity trajectory. The main objective of this work is to discuss the impossibility of separating the body preparation and the poetic "products" emerged along the work. As the text's bibliography, we used the autors: Cohen (2004), Freitas (2011), Jacques (2002 and 2008), Miranda (2008), Rancière (2008) and Silva (2005). The project is developed in "safe spaces" (classroom) and "risk spaces" (city), with consciousness body technical experimentations, exploring the relationship between the participants among themselves and with the public space, about their physicality and social characteristics, causing different poetics. The community is involved directly and indirectly in the experimentation process on the street, having the role of the viewer and the artist mixed and the participants finding other dances in themselves.

Keywords

City. Dance. Urban Interventions. Games. Improvisation. 
Como se preparar para o que não se sabe, para o desconhecido, para o instantâneo? Como se munir corporalmente de técnicas para realizar intervenções urbanas, dança na rua e performances? Como trabalhar na ideia de work in progress? (COHEN, 2004) Esses são alguns dos questionamentos que perpassam pelo grupo que constitui o Caminhos da Dança na Rua, projeto de extensão do curso de Dança-Licenciatura da Universidade Federal de Pelotas.

Em virtude do encontro e compartilhamento de duas arquitetas-bailarinas ou bailarinas-arquitetas, ambas com interesse na interdisciplinaridade das áreas, nasce o Caminhos da Dança na Rua que, como o próprio nome já indica, é um espaço-tempo que contempla as inquietações e desejos acerca da relação poética das pessoas entre si e com o espaço público - arquitetônico e urbano. O principal objetivo do grupo é experimentar movimentos corporais a partir do espaço urbano. O presente texto trata das perspectivas poéticas surgidas nesse "caminho" percorrido na cidade de Pelotas nos anos de 2015 e 2016, entendendo que a estética dos trabalhos tem relação direta com o processo e com os corpos-espaços (MIRANDA, 2008) que por ele passam.

As ações do grupo são pensadas como "corpografias urbanas", ou seja:

parte da hipótese de que a experiência urbana fica inscrita, em diversas escalas de temporalidade, no próprio corpo daquele que a experimenta, e dessa forma também o define, mesmo que involuntariamente. (JACQUES, 2008, s.p.)

Tal concepção está relacionada ao conceito de "Corpo-Espaço", de Miranda (2008, p. $24)$, que implica na fluidez das fronteiras cor- porais e do espaço. A autora compreende o movimento, o corpo e o espaço "permanentemente imersos em mútuas relações de transformação", como Jacques (2008), que entende o corpo como elemento inseparável da cidade. A "corpografia urbana" sugere, então, que o corpo e a cidade se configuram mutuamente, assim, a cidade fica inscrita nos corpos que com ela interagem, passando a ser, simultaneamente, esses mesmos corpos: somos a cidade que experienciamos.

As ações do grupo se iniciaram a partir de divulgação em redes sociais, atendendo ao chamado por interessados(as) em parkour ${ }^{1}$, performance e intervenções urbanas. Um grupo com corporeidades diversas se formou, com o intuito de "experimentar a rua". Nessa congruência, alguns integrantes almejavam tratar sobre ações mais artísticas, plásticas, estéticas. Já outros, sobre movimentos de cunho político, que discutissem a respeito do espaço e da sociedade, o que ocasionou uma diversidade de demandas e estéticas (figura 1).

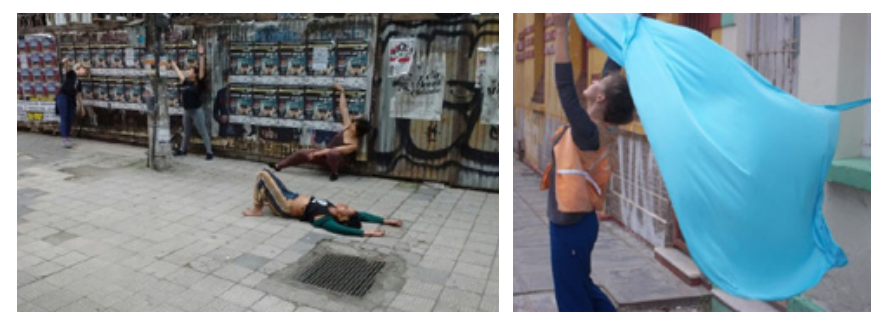

Fig. 1: Grupo com diferentes cunhos: político e estético. Fonte: Carmen Hoffmann e Débora Allemand, 2015

As fotografias e vídeos das experimentações deixam rastros do trabalho efêmero da dança na cidade e nos auxiliam na rememoração e recriação, sob a perspectiva poética das experiências nos diferentes espaços e momentos trabalhados no Caminhos da Dança na Rua.

1 Parkour é um esporte urbano, cujo princípio é se mover de um ponto a outro o mais rápido e eficientemente possível, usando principalmente as habilidades do corpo humano. 


\section{Prepar-ação:} produto -processo

Os "produtos" que serão aqui discutidos são fruto de um processo de experimentação, considerando que na rua sempre se está "apresentando" algo que pode vir a ser assistido por algumas pessoas, dependendo do lugar onde é realizado. O grupo trabalha em diferentes espaços públicos da cidade, com quantidades variáveis de transeuntes e também utiliza espaços internos da universidade para tais experimentações.

A partir do uso dos figurinos na rua, surgiram ideias sobre a relação do tecido com o espaço, nas quais as possibilidades de interação se tornavam estímulos para a criação do movimento (figura 2). Além disso, artefatos intrínsecos aos espaços públicos, como caixas de embalagens de mercadorias (figura 3), animais que circulam pela cidade (figura 4), natureza urbana, entre outros, incitavam movimentos diversos que compunham de forma inusitada a cena que se estabelecia no momento das ações artísticas.
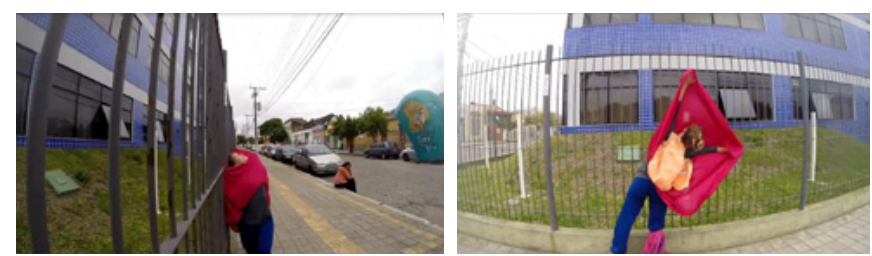

Fig. 2: Figurino como mote para criação do movimento na rua. Fonte: Débora Allemand, 2015.
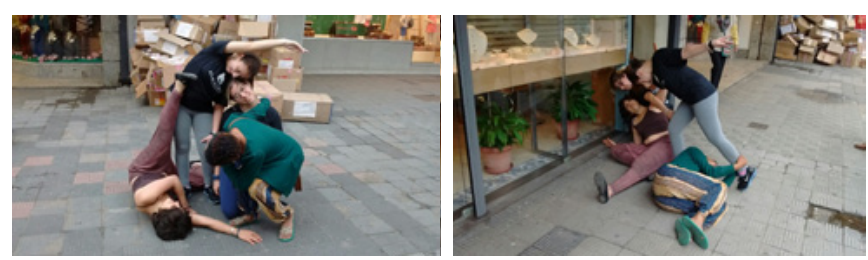

Fig. 3: Encontro com caixas de papelão no espaço central da cidade. Fonte: Carmen Hoffmann, 2015.
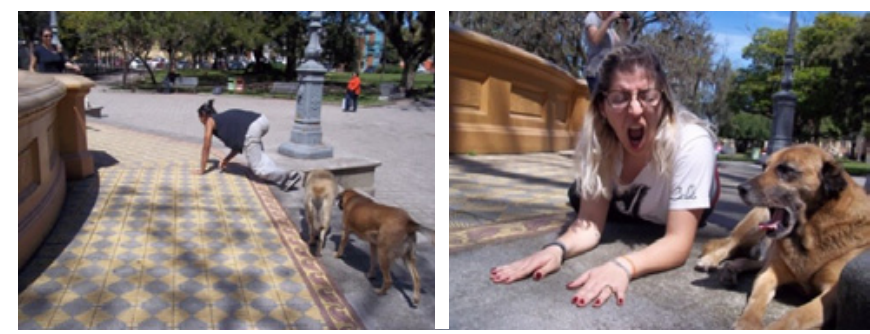

Fig. 4: Ações lúdicas a partir do movimento dos cachorros na rua. Fonte: Taís Bastos Botelho, 2015.

No entanto, para falar do "produto", é preciso situar o leitor sobre o processo, pois "o produto, na via do work in process, é inteiramente dependente do processo, sendo permeado pelo risco, pelas alternâncias dos criadores e atuantes e, sobretudo, pelas vicissitudes do percurso". (COHEN, 2004, p. 18) As intervenções do projeto remetem diretamente ao proposto pelo coreógrafo pós-moderno Merce Cunningham, nos anos 1940, quando questionou:

\begin{abstract}
A ideologia da dança moderna substituindo a narrativa única pela estrutura fragmentada ou episódica; o uso do palco convencional italiano pelas mais inusitadas opções cênicas (topo de arranha-céus, estacionamentos, galerias de arte, praças, ringue de boxe); o processo criativo linear e pessoal pelo uso intensivo da experimentação e improvisação (BANES apud SILVA, 2005, p. 105).
\end{abstract}

Atualmente, os encontros do Caminhos da Dança na Rua são mesclados entre "espaços seguros" - sala de aula - e "espaços de risco" cidade - (FREITAS, 2011) - figura 5. Os "corpos disponíveis", com e sem experiências intrinsecamente ligadas à dança, participam tanto dos laboratórios de experimentações corporais em sala de aula, quanto das saídas a campo desempenhadas nas ruas de Pelotas. 

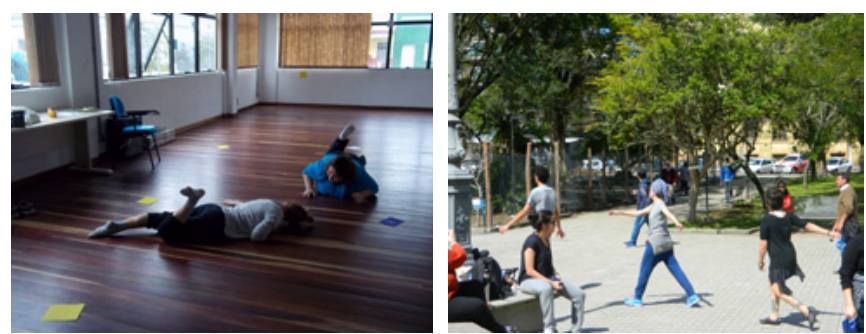

Fig. 5: Espaço seguro e espaço de risco: sala de aula e rua. Fonte: Débora Allemand, 2015.

Os espaços de sala de aula, com pisos adaptados para práticas de dança, possibilitam uma breve experimentação das técnicas voltadas à educação somática ${ }^{2}$. Visou-se trabalhar com alavancas corporais, respiração, trabalho de queda e recuperação, contato e improvisação, atenção aos estímulos etc. Por possibilitar uma maior consciência corporal dos participantes, as técnicas citadas correspondem aos objetivos do projeto no momento.

Já o espaço da cidade é, para nós, um lugar "desconhecido" e, para conhecê-lo, é necessária uma observação atenta sobre ele e sobre as pessoas e atividades que nele vivem e acontecem. Um lugar de experimentação, de abertura para que o movimento surja a partir da relação do corpo no espaço e não a partir de concepções de movimentos prévios àquele local. Um lugar que muda constantemente e, por isso, a "preparação" também inclui estar atento às mudanças. Com esse intuito, a técnica viewpoints ${ }^{3}$ auxiliou o grupo no processo

\footnotetext{
2 A educação somática vem sendo utilizada por alguns artistas da dança para o tratamento e prevenção de traumas e lesões. Ela é usada também por ser uma técnica capaz de possibilitar a ampliação das capacidades expressivas dos praticantes, desenvolvendo a qualidade da presença cênica e trazendo a consciência do movimento. O principal objetivo da educação somática é fazer emergir formas e posturas mais eficazes, ou seja, máximo de aproveitamento com o mínimo de esforço. (STRAZZACAPPA, 2012)

3 Viewpoints é uma técnica de improvisação e composição criada por Anne Bogart e Tina Landau. "A base dessa técnica é a decomposição da percepção, análise e construção de significados, em cena, pelo movimento - portanto, pela relação do corpo com o espaço e com o tempo - a partir de nove
}

de observação, estimulando o movimento em relação ao outro e ao espaço (figura 6).

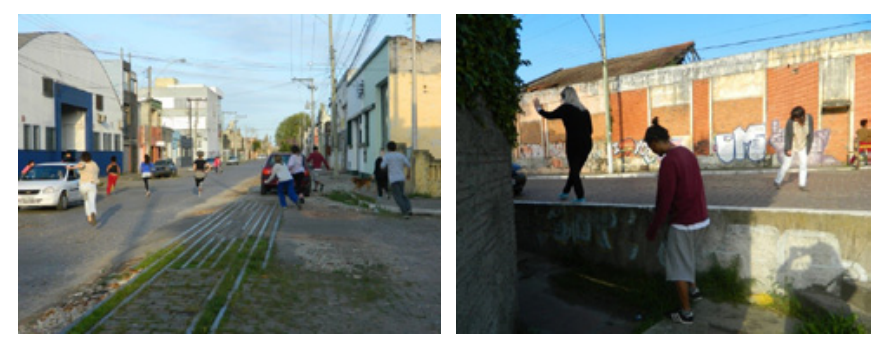

Fig. 6: Realização do exercício Viewpoints. Fonte: Débora Allemand e Alice Braz Iturriet, 2015.

Assim como sugere Cohen (2004), os performers que realizam esse perfil de intervenções estão expostos a riscos de ordem física e psíquica, incluindo a possibilidade da não conclusão do trabalho em um produto final. Ainda assim, o processo fica inscrito nos corpos dos participantes, independente dos papéis que tenham desempenhado na ação.

A improvisação 4 oportuniza uma liberdade criativa e relacional com as movimentações e corpos ali dispostos. Surge a partir de temas, exercícios de dinâmicas grupais, como também da relação do cotidiano de cada corpo, cada indivíduo com a arquitetura/local onde o grupo se encontra atento e reflexivo, em constante movimento corporal e político.

Espaços-tempos que provocam diferentes relações e modificações em cada indivíduo. Espaços-tempos imbuídos de histórias que se cruzam com as histórias dos que conosco se propõem a dialogar, gingar. Espaços-tempos muitas vezes despercebidos no cotidiano, mas que no momento da experiência e do encontro se tornam espaços-corporais, pela intenção de

perspectivas: tempo, duração, resposta cinestésica, repetição, forma, gesto, arquitetura, relação espacial e topografia". (FERREIRA; FALKEMBACH, 2012, p. 71)

4 "A improvisação em dança pode ser tomada como uma forma e não uma ferramenta de organização do Sistema Dança, podendo ser considerada, também, como um tipo de espetáculo e não somente como um meio de produzir material para coreografias." (MARTINS, 2003, s.p.) 
sê-los ainda que momentaneamente e assim:

Um ritmo próprio surge dos percursos, uma nova temporalidade surge do próprio caminhar. A ginga e a dança parecem diluir os espaços, transformando o espaço em movimento, pois temporalizam o espaço. A arte do tempo, a música, e a arte do espaço, a arquitetura, se casam na dança, arte do movimento. (JACQUES, 2002, p. 61)

Ainda que o projeto "deixe a rua nos levar", nota-se que os participantes do grupo - principalmente os que são estudantes e professores de dança - buscam a organização e até certa sistematização estética, tentando definir certas limitações para as performances que são "programadas" e divulgadas, para as quais há convites para que pessoas assistam e participem, ainda que saibamos que durante os "ensaios" esta ação já esteja acontecendo com "público participante" ou "espectador emancipado". (RANCIĖRE, 2008) Já os participantes que são de outras áreas, diferente das artes cênicas, não estão tão preocupados com o "resultado final" e dão mais atenção ao processo.

\section{Espectador-participante}

A prepara-ação pressupõe fazer um trabaIho corporal anterior à cena e ao contato com o público. Mas, no caso das intervenções urbanas do Caminhos, não existe essa "cena" posterior à preparação, considerando ainda que o espectador também é de outra ordem, podendo ser transeunte, por exemplo. Então, a preparação corporal está misturada e é entendida como o próprio jogo, que define regras

5 Aqui se faz referência à música "Pra rua me levar", de Ana Carolina, e ao VIII Seminários de Dança de Joinville, o qual teve a temática "Deixa a Rua me Levar" também baseado na mesma música. antes, mas também inventa soluções durante o próprio jogar, ao se deparar com situações inusitadas que solicitam respostas instantâneas. $O$ trabalho com jogos ${ }^{6}$ possibilita que os participantes possam exercitar a disponibilidade dos corpos para o que pode lhes causar experiência ${ }^{7}$ naquele espaço-tempo.

As mudanças nas formas como a cena se organiza vêm desde Cunningham, na década de 1940, com a negação ao espetacular, além da não hierarquização dos bailarinos. Com isso, o público também foi modificando seu olhar e aprendendo a apreciar novas estruturas (figura 7), ganhando certa autonomia no sentido de escolher seu foco, com maior abertura para diferentes leituras, interpretações e conexões. (SILVA, 2005)
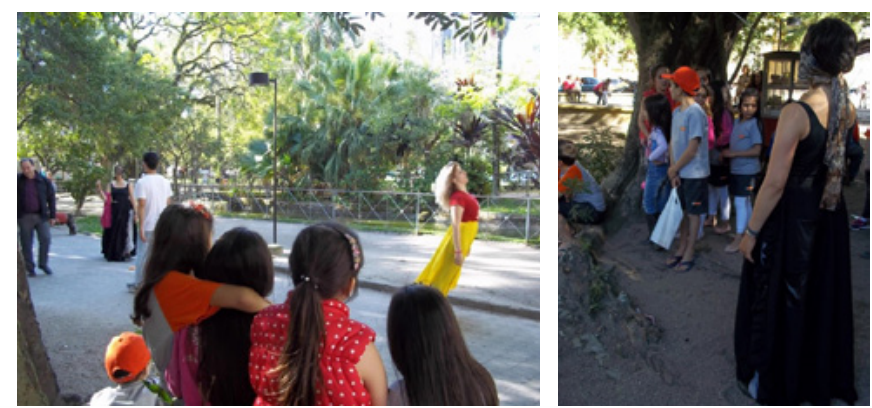

Fig. 7: "Público" formado por crianças que visitavam a Feira do Livro. Fonte: Débora Allemand, 2015.

Tal modificação se desenrola ainda na atualidade na qual, cada vez mais, o espectador vem aderindo ao papel de participante ativo

\footnotetext{
6 No jogo, cria-se um ambiente no qual as pessoas se sintam livres para experimentar a partir de uma atividade que promova a espontaneidade. Essa experiência acontece através do envolvimento do grupo no próprio jogo, que é capaz de desenvolver técnicas e habilidades próprias para o jogo através do ato de jogar. Durante o jogo, o jogador é livre para inventar soluções para qualquer problema que o jogo apresente, desde que seja para atingir o objetivo e que obedeça às regras estipuladas anteriormente. Os jogadores se tornam ágeis, alertas, prontos e desejosos de novos lances ao responderem aos diversos acontecimentos acidentais simultaneamente. (SPOLIN, 2005)
}

7 A experiência é corporal, é visceral, "é o que nos passa, o que nos acontece, o que nos toca". (BONDÍA, 2002, p. 21) 
na criação, chegando inclusive a uma relativização de seu lugar e do lugar do artista, visto que este primeiro sente, lê, cria. (LADEIRA, 2015) Ou seja, o espectador é mais que um corpo que assiste, ele é, em si, um corpo que comunica, (re)age, expressa algo a todo instante. Esse processo de autonomia de fruição e a aproximação entre público e proponentes são ideias partícipes do que Rancière se refere como um processo de emancipação do espectador:

A emancipação parte do [...] princípio da igualdade. Ela começa quando dispensamos a oposição entre olhar e agir e entendemos que a distribuição do próprio visível faz parte da configuração de dominação e sujeição. Ela começa quando nos damos conta de que olhar também é uma ação que confirma ou modifica tal distribuição, e que "interpretar o mundo" já é uma forma de transformá-lo, de reconfigurá-lo. $O$ espectador é ativo, assim como o aluno ou o cientista. Ele observa, ele seleciona, ele compara, ele interpreta. Ele conecta o que ele observa com muitas outras coisas que ele observou em outros palcos, em outros tipos de espaços. Ele faz o seu poema com o poema que é feito diante dele. Ele participa do espetáculo se for capaz de contar a sua própria história a respeito da história que está diante dele. $(2008$, s. p.)

Percebe-se uma linha tênue entre os estados cotidiano e extracotidiano (BARBA e SAVARESE, 1995) durante as performances, considerando que a vida cotidiana está muito presente nos exercícios. Isso ocorre porque as ações se realizam em espaços por onde passam pessoas todo o tempo e que, muitas vezes, param para conversar com algum conhecido do grupo ou para perguntar o que está acontecendo. "Num imbricamento intenso entre criador-criatura-obra, a cena dá tessitura às rupturas pós-modernas, estabelecendo continuum nas descontinuidades, permeando intensamente as ambiguidades arte/vida". (COHEN, 2004, p. XXIV) Por isso, a ideia do Caminhos é justamente a de gerar uma concentração que não se feche em si mesma, mas que se adeque a responder aos estímulos do entorno ao mesmo tempo em que se mantém em estado extracotidiano.

Sendo o Caminhos um projeto que majoritariamente acontece na rua, seus participantes ficam expostos a toda riqueza e risco que os espaços públicos podem proporcionar. Desse modo é possível perceber uma espécie de relação de espelho entre caminhantes conscientemente partícipes do projeto e os caminhantes passantes, na qual, de algum modo, ambos afetam e são afetados. Estar na rua é $\mathrm{t}(\mathrm{r})$ ocar constantemente e viver.

Assim, o processo e a resposta que a cidade fornece aos corpos definem os próximos passos. Isso faz com que se desvende e se invente uma Pelotas (figura 8) que surge a partir do contato dos corpos-caminhantes com o corpo da Arquitetura, onde um transforma o outro constantemente, atingindo, com isso, os transeuntes que passam pela rua.
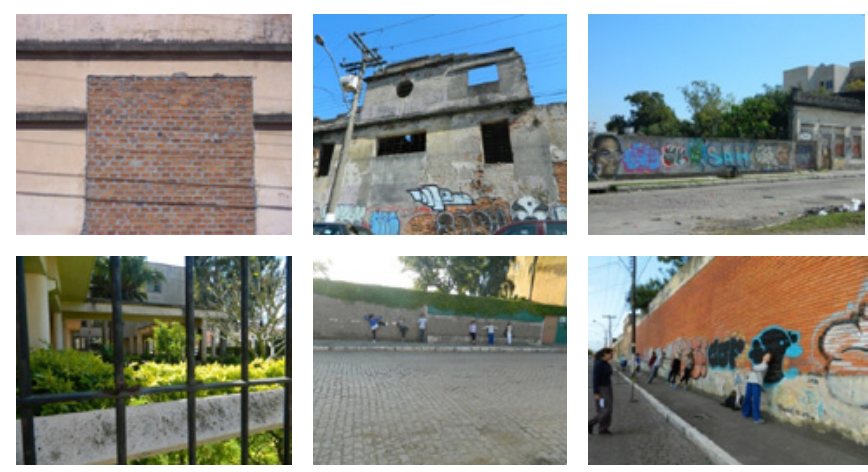

Fig. 8: Paredes, muros e barreiras no Porto de Pelotas. Fonte: Débora Allemand, 2015. 


\section{Considerações caminhantes}

Sabe-se que a proposta de intervenção urbana não é inovadora, já que desde 1950 muitos movimentos de arte lutam pelo seu espaço na cidade, discutindo e reinventando o que é coreografia e o que é dança. Ainda assim, para o curso de Dança da UFPel, o projeto veio preencher uma lacuna e foi possível, por meio dele, reunir artistas de diversas áreas e com diferentes objetivos no contato do corpo com a rua, também rediscutindo os papéis de espectador e artista, cena e pré-cena.

Entende-se que o mais importante para $o$ grupo seja produzir movimentos que tenham relação com o espaço. Esse espaço por vezes é físico e por vezes é fruto de uma relação que acontece na cidade, junto às pessoas que passam na rua ou as atividades que estão acontecendo ali. Tratam-se de estímulos distintos dos que se têm nos espaços tradicionais (teatros, salas de espetáculo), o que proporciona aos participantes o encontro com outras danças.

Nesse sentido, a comunidade é envolvida direta e indiretamente no processo de experimentação na rua. Muitos questionam o que está acontecendo, outros até "entram na dança" e conversam corporalmente com os participantes e alguns somente observam os caminhos que a dança toma. Os papéis de espectador e artista ficam borrados, misturados. Vivenciar a rua de modos não habituais é, em si, uma experiência extracotidiana com potencial de incitar os transeuntes a perceberem outras possibilidades de vivências poéticas, estimulando a fruição em arte pela estranheza, arrancando-os de um possível estado de inércia. Então, experimentantes e passantes criam, fazem e refazem conexões a todo momento.
A conexão entre o grupo participante permitiu uma exploração abrangente do corpo que dança em movimento com arte na rua. Os integrantes estão motivados e envolvidos com o projeto a ponto de buscarem possibilidades de participação em eventos da mesma natureza em outras cidades e Estados.

As ações caracterizam-se como desdobramentos desafiantes das práticas do Curso de Dança Licenciatura, pois sugerem algo que se estende para além das "fronteiras" do curso institucional, para além dos espaços tradicionais, possibilitando que a curiosidade alheia sirva-se dos conhecimentos que dali emergem, despertando interesses, alimentando inclinações e simpatias. Ou seja, existe também para difundir saberes e experiências.

Por fim, seja pela curiosidade ou pelo incômodo, o Caminhos tem se mostrado, apresentando outros modos de danças possíveis junto ao ato de (re)descobrimento de si e do mundo. O grupo está sendo percebido e tem se inserido em programações e eventos propostos pela universidade. $O$ projeto disponibiliza um acervo visual e audiovisual que pode ser acessado na página de rede social: https://www. facebook.com/caminhosdarua/?fref=ts.

\section{Referências}

BARBA, Eugênio; SAVARESE, Nicola. $A$ arte Secreta do Ator. São Paulo, Campinas: Hucitec/UNICAMP, 1995.

BONDÍA, Jorge Larrosa. Notas sobre a experiência e o saber de experiência. Rev. Bras. Educ. [online]. 2002, n.19, pp. 20-28. 
COHEN, Renato. Work in Progress na cena contemporânea: criação, encenação e recepção. 2 ed. São Paulo: Perspectiva, 2004.

FERREIRA, Taís; FALKEMBACH, Maria Fonseca. Teatro e Dança nos anos iniciais. Porto Alegre: Mediação, 2012.

FREITAS, Vanilto Alves de. Para Uma Cidade Habitar Um Corpo: Proposições de Uso do Espaço Urbano e seus Acréscimos na Formação do Artista Cênico. Dissertação de Mestrado Programa de Pós-graduação em Artes da Universidade Federal de Uberlândia. Uberlândia: UFU, 2011.

JACQUES, Paola Berenstein. Quando o Passo vira Dança. In: VARELLA, Drauzio; BERTAZZO, Ivaldo; JACQUES, Paola. Maré, Vida na Favela. Rio de Janeiro: Casa da Palavra, 2002.

JACQUES, Paola Berenstein. Corpografias urbanas. 2008. Disponível em: http:// www.vitruvius.com.br/revistas/read/arquitextos/08.093/165. Acesso em: 26/08/2016.

\section{LADEIRA, J. C. P. FILEIRA G, ACENTO 18 OU:} O lugar do espectador na criação dos espetáculos de dança de grupos independentes da cidade de Pelotas-RS. 2015.

MARTINS, C. F. Improvisação em dança: sistemas e evolução. Disponível em http://idanca. net/improvisacao-em-danca-sistemas-e-evolucao/. Acesso em: 19/08/2016.

MIRANDA, Regina. Corpo-espaço: aspectos de uma geofilosofia do movimento. Rio de Janeiro: 7Letras, 2008.
RANCIÈRE, J. O espectador emancipado. Questão de Crítica: revista eletrônica de crítica e estudos teatrais. Vol. I, $n^{\circ} 3$, mai 2008. Acessado em 07 ago 2016. Disponível em http:// www.questaodecritica.com.br/2008/05/o-espectador-emancipado/.

SILVA, Eliana Rodrigues. Dança e pós-modernidade. Salvador: EDUFBA, 2005.

SPOLIN, Viola. Improvisação para o teatro. 5. Ed. São Paulo: Perspectiva, 2005.

STRAZZACAPPA, Márcia. Educação somática e artes cênicas: princípios e aplicações. Campinas, SP: Papirus, 2012.

Recebido: 31/08/2016 Aprovado: 23/12/2016 